artelogie

\section{Artelogie}

Recherche sur les arts, le patrimoine et la littérature de l'Amérique latine

\section{$4 \mid 2013$}

Fêtes et célébrations en Amérique latine

\title{
Congressos Eucarísticos : Cristo Rei celebrado no Brasil da primeira metade do século XX
}

Congrès eucharistiques: Christ Roi célébré au Brésil dans la première moitié du $\mathrm{XXe}$ siècle

\section{Artur Cesar Isaia}

\section{(2) OpenEdition}

\section{Journals}

Edição electrónica

URL: https://journals.openedition.org/artelogie/6506

DOI: $10.4000 /$ artelogie.6506

ISSN: 2115-6395

Editora

Association ESCAL

Refêrencia eletrónica

Artur Cesar Isaia, «Congressos Eucarísticos : Cristo Rei celebrado no Brasil da primeira metade do século XX», Artelogie [Online], 4 | 2013, posto online no dia 02 fevereiro 2013, consultado o 01 dezembro 2021. URL: http://journals.openedition.org/artelogie/6506 ; DOI: https://doi.org/10.4000/ artelogie.6506

Este documento foi criado de forma automática no dia 1 dezembro 2021.

Association ESCAL 


\section{Congressos Eucarísticos : Cristo Rei celebrado no Brasil da primeira metade do século XX}

Congrès eucharistiques: Christ Roi célébré au Brésil dans la première moitié du $\mathrm{XXe}$ siècle

Artur Cesar Isaia

\section{Introdução}

1 Os Congressos Eucarísticos surgem na Europa do século XIX, em um momento particularmente difícil para a manutenção da supremacia católica sobre a sociedade. Incentivados pela hierarquia como atestado público de reconhecimento e veneração à presença sacramental de Cristo, esses Congressos estão intimamente relacionados com a representação da realeza de Cristo. A representação da realeza de Cristo ganhou ímpeto ainda maior com o reconhecimento da festa de Cristo Rei pelo papa Pio XI, pela bula Quas Primas no ano de 1925. Em uma conjuntura de laicização acentuada do poder, os Congressos Eucarísticos apareciam como ocasiões festivas por excelência, nas quais a igreja católica mobilizava um arsenal imagético extremamente voltado para o reconhecimento de um poder que se colocava acima do tempo humano e das oscilações das vontades coletivas. Representada acima e alheia às fórmulas políticas, a representação de Cristo Rei acenava para o reconhecimento da providência divina atuando soberanamente sobre a história e sobre os homens. Um poder contra o qual, tanto a ideia de soberania das maiorias quanto todas as formas de autocracia eram reconhecidas como inoperantes. Esses Congressos ritualizavam (à medida que reiteravam) a representação de um Deus Todo-Poderoso e Senhor da história, cujo triunfo escatológico estava anunciado nas escrituras e reconhecido na tradição da igreja. Essa representação da realeza de Cristo estava intimamente relacionada à encarnação do Verbo e ao mistério trinitário. Somente um Deus que aceita a humanidade poderia ter atributos régios. Das três pessoas que formam o mistério 
trinitário, Cristo, pelo seu atributo humano poderia ser rei, como se lê na epístola de São Paulo aos Colossenses, I (12-20), ao dar graças a Deus pelo "Reino do Filho de seu amor". Na própria bula na qual institui a festa de Cristo Rei, o papa coloca em evidência a comemoração do $16^{\circ}$. centenário do Concílio de Niceia, o qual proclamando o dogma da consubstancialidade trinitária, inseriu no Credo católico as palavras : "cujo Reino não terá fim", afirmando "a dignidade real de Cristo"1. Os Congressos Eucarísticos, celebrando publicamente a realeza de Cristo e a sua presença sacramental afirmavamse como momentos, a um só tempo de afirmação do poder de mobilização católico e de contraponto ao laicismo e à relativização da presença da igreja no mundo moderno.

\section{Congresso Eucarístico do Centenário da Independência : as comemorações do "Brasil Católico"}

2 As comemorações do centenário da independência brasileira em 1922 deram-se em meio a uma conjuntura particularmente difícil para o governo Epitácio Pessoa. A contestação ás eleições que indicaram a vitória de Artur Bernardes em março de 1922 e a sublevação militar ocorrida na própria capital em julho do mesmo ano desenhavam um clima particularmente difícil e indefinido para as comemorações previstas. O Rio de Janeiro, que passava por transformações urbanísticas radicalmente importantes, como a derrubada do Morro do Castelo, que se modernizava para receber delegações estrangeiras, acenava para um panorama incerto a poucos meses das comemorações oficiais. Neste contexto a igreja católica, como contraponto, colocava à disposição do estado a sua força, não apenas de mobilização política, mas seu patrimônio simbólico, que remetia para a sedimentação da união nacional e para o público acatamento ao poder instituído. Por outro lado, a igreja católica buscava ocupar espaços políticos, passando por cima do indiferentismo religioso das elites políticas e do laicismo vigente desde a proclamação da república. Assim, reveste-se de particular importância a presença da igreja católica nas celebrações do centenário da independência. Se a presença da igreja não se fazia sentir na programação oficial das comemorações, a hierarquia eclesiástica vai organizar um espetáculo de rua, capaz de tornar explícita a sua capacidade de arregimentação e a exposição de seus bens simbólicos mais caros, para demonstrar a sua força e sua capacidade agregadora e pacificadora. Assim, as comemorações católicas do centenário de independência vinculam-se à tônica de seu discurso na primeira metade do século XX. Neste lapso de tempo, o discurso católico perseguia a imagem de um Brasil, cuja identidade advinha, antes de tudo da sua catolicidade, vista como a chave explicativa para o acesso à realidade nacional.

Os Congressos Eucarísticos eram ocasiões em que abundavam no discurso dessa hierarquia as imagens de um "Brasil católico", representando o povo brasileiro como capaz de guardar os ensinamentos legados pelos antepassados, qualificando-se como baluarte da recristianização do mundo. Essa representação de um Brasil essencialmente católico, no qual povo, estado e igreja acabavam, sem contornos definidos, compartilhando valores e inimigos, salta aos olhos nos pronunciamentos da hierarquia católica durante as comemorações do centenário da independência. Nessa ocasião, o episcopado brasileiro, reunido no Rio de Janeiro, lança uma Carta Pastoral Coletiva, onde constrói a imagem de uma terra, cujo marco fundador e presença civilizadora eram remetidos à igreja católica. $O$ documento enxergava, inclusive, antes na cruz do 
que na sucessão de pavilhões que identificaram historicamente o Brasil, o verdadeiro símbolo nacional :

4 Apenas descoberta nossa querida pátria, sobre ela desceram a 26 de abril e no dia $1^{\circ}$. De maio de 1500, as bênçãos de Deus pela oblação do corpo e sangue de Jesus nas aras improvisadas pelo zeloso frei Henrique de Coimbra ante o gentio estupefato. Qual pavilhão protetor no solo ainda virgem do Brasil ergue-se a mandado de Pedro Álvares Cabral, em Porto Seguro, majestosa cruz, feita de madeira das soberbas florestas de nossa terra! Ei-lo, o descobridor do Brasil, levantando pra a perpétua memória de posse divina o glorioso padrão, que há vente séculos marca as conquistas do Filho de Deus. A ele, pois pertence desde a sua origem a Terra de Santa Cruz. ${ }^{2}$

5 A referência ao "nascimento" do Brasil com a primeira missa é recorrente em vários documentos da hierarquia católica do período, que gravitava em torno de uma narrativa mítica da história nacional, intimamente aparentada com a matriz historiográfica de Varnhagen, na qual a catolicidade e a lusitanidade apareciam como elementos distintivos ${ }^{3}$. Assim, D. João Becker, arcebispo de Porto Alegre, na missa que inaugurou o Congresso, apelava para a mítica imagem da primeira missa como sendo o Primeiro Congresso Eucarístico celebrado em terras brasileiras :

6 Apenas aportaram as caravelas lusitanas às praias viridentes da Terra do Cruzeiro, celebrou Frei Henrique de Coimbra, à sombra de majestosa cruz, o santo sacrifício da missa. Não seria esse o nosso primeiro Congresso Eucarístico ? Pois os congressistas eram Pedro Álvares Cabral, sacerdotes e marinheiros portugueses, assim como os aborígenes das vizinhanças. Alterosas palmeiras estendiam seus leques por cima dessa estranha assembleia. Orquídeas e cipós floridos ornavam o altar improvisado. 0 canto dos pássaros multicores enchia os ares, e os assistentes, dobrando o joelho, diziam contritos : Devotamente Vos adoramos, divindade oculta : Adoro te devote latens Deitas. ${ }^{4}$

7 A descrição que a imprensa católica fazia dos atos litúrgicos, das concentrações populares organizadas pela igreja e das pessoas dos membros da hierarquia, reforçava a identidade de uma instituição que se representava como capaz de guardar íntima e monopólica familiaridade com Aquele que reinava soberanamente sobre o Brasil. 0 "Mensageiro do Coração de Jesus", órgão oficial da organização Apostolado da Oração e que circulava em todo o território nacional, é uma fonte que exemplifica esse projeto de evidenciar a supremacia das "coisas da igreja", sobre as contingentes instituições e planos humanos. Por exemplo, no Congresso Eucarístico do Centenário da Independência, celebrado no final de setembro de 1922, evidenciou-se a tentativa do clero em dar centralidade ao evento, colocando-o acima das festas cívicas. Ao descrever a procissão do Congresso, o "Mensageiro do Coração de Jesus" frisava que a mesma era um ato público inconfundível com qualquer outro que se resumisse ao aspecto político, cívico ou meramente lúdico. A procissão era descrita como uma colossal manifestação de adoração dos súditos brasileiros ao Divino Rei, por isso mesmo seu esplendor material, seu significado último e a multidão que mobilizara, era em tudo infinitamente superior aos atos públicos que a capital do país presenciara por ocasião mesmo do centenário da independência :

8 Mal o Divino Rei no seu carro dobrou a Av. Beira Mar (...) ouviu-se a mais fervorosa oração de que o Rio tem notícia... Viva Jesus Cristo ! Viva o Brasil Católico ! (...) E ao chegar o carro com o Santíssimo na Praça Maruá : Viva o Rei e Senhor dos Exércitos ! Viva o Rei e Senhor do Brasil. ${ }^{5}$ 
9 As excelências da instituição eclesial, capaz de emprestar às organizações humanas a simetria e a ordem que caracterizavam seu edifício doutrinário e que se refletiam no brilho e organização de seu culto eram louvadas em oposição ao caráter sempre discutível das instituições humanas e do torvelinho caótico que as manifestações de rua meramente civis não eram capazes de evitar. Assim, comparando as cerimônias religiosas, com as festas cívicas do centenário da independência escreve o "Mensageiro" : "Em contraste com as festas cívicas do dia, na catedral reinavam organização e ordem perfeita. A imprensa foi unânime em registrá-lo." ${ }^{\circ}$ Dessa forma, o "Te Deum" que aconteceu a 7 de setembro de 1922, portanto simultaneamente às comemorações oficiais, era visto pelo "Mensageiro" evidenciando a sua supremacia sobre as festas programadas pelo poder civil. Não poupava palavras, o "Mensageiro", para salientar o brilho da cerimônia, que em tudo remetia a outra ordem, diferente da meramente humana e circunstancial ${ }^{7}$, conforme notou Elias Canetti $^{8}$ ao referir-se aos aspectos externos do catolicismo tridentino.

10 Em Porto Alegre, D. João Becker fazia eco a D. Sebastião Leme, elemento de proa da ofensiva católica da primeira metade do século XX, o qual salientava o caráter religioso e patriótico do Congresso de 1922, frisando a distinção em relação às comemorações oficiais. A laicidade das comemorações oficiais não poderia remeter ao verdadeiro patriotismo, este visto indissoluvelmente ligado à religião católica. Ao mesmo tempo reiterava o arcebispo o reconhecimento da realeza de Cristo sobre o Brasil, sempre vista como inatacável, mesmo pelo estado laico, porque reconhecida no coração do povo (católico) :

11 Essencialmente religioso e patriótico - como em sua circular diz o ilustre Sr. D. Sebastião Leme - o congresso eucarístico do Centenário é também de grande alcance social, porque, visando dilatar e estimular o reinado da eucaristia, fonte e centro da vida cristã, fará sentir na sociedade uma maior exuberância dos frutos benéficos do evangelho. ${ }^{9}$

12 Por outro lado, salientava D. João Becker no Te Deum de 07 de setembro de 1922, que não haveria condições de vislumbrar-se o progresso do país, se povo e estado não reconhecessem o reinado de Cristo sobre o Brasil e que não haveria patriotismo verdadeiro laicizando-se o amor à pátria e esquecendo-se do catolicismo, visto como pedra angular da nacionalidade :

13 A grandeza da pátria exige nossa fidelidade a Jesus Cristo. Rei imortal dos povos, ante cuja inefável majestade, se rendem todas as armas, se inclinam todas as bandeiras, se humilham todos os cetros, e que pela sua igreja, tão insignes benefícios lhe prodigalizou. Queremos servir, defender e amar a pátria ; mas a pátria engrandecida pelo nosso trabalho, pelas nossas virtudes e pela religião dos nossos antepassados, a pátria nobre, digna e íntegra. ${ }^{10}$

\section{Congressos Eucarísticos : a celebração da realeza de Cristo sobre o estado laico}

14 As falas da hierarquia católica da primeira metade do século XX persistiam na representação de uma sociedade que se queria uma, distante do império das individualidades, marcada pela solidariedade orgânica e abençoada pela igreja católica. Esta, à medida que a sociedade passava a aprofundar nos grandes centros urbanos a 
vivência de uma situação pluralista, intensificava no seu discurso a busca por tornar óbvia a representação de um Brasil identificado historicamente com o catolicismo. Assim, ao mesmo tempo em que rejeitava toda a representação da sociedade baseada na ideia de "mercado político", passava a opor-se a qualquer tentativa de pensar o Brasil fora da vinculação com o catolicismo. A igreja persistia em uma representação do social, onde toda a ideia de mercado político é banida em favor de representações elaboradas a partir dos princípios de autoridade e consenso ${ }^{11}$. A representação de um Brasil católico integrava a de uma sociedade pensada a partir de uma concepção orgânica, onde a harmonia, a solidariedade, a ordem e o comando de um centro forte apareciam como evidências maiores de adequação ao direito natural e à verdade revelada. A hierarquia e parte do laicato católico passavam já na República Velha, a criticar abertamente os princípios julgados artificiais, porque eivados de "liberalismo anticristão" e antagônicos às "raízes da nacionalidade", introduzidos a partir de 1891. Após os anos 1920, ganham forças no discurso católico as propostas de "regeneração, depuração, reordenação", que acenavam explicitamente para a matriz autoritária ao regime de 1891. É flagrante a filiação de D. Sebastião Leme, D. João Becker e de vultos proeminentes do laicato, como Jackson de Figueiredo e Tristão de Athayde, às ideias de autores, que criticando o liberalismo da República Velha, propunham uma solução acorde com a "realidade nacional". As ideias de Alberto Torres, Oliveira Vianna e, posteriormente, Francisco Campos, guardam um parentesco muito nítido com as propostas evidenciadas nos pronunciamentos do clero e laicato católicos da primeira metade do século ${ }^{12}$. Insistia o discurso oficial católico em qualificar a igreja como a instituição mais importante para a manutenção da unidade, da paz e dos ideais tidos como nacionais. Para isso lançava mão de uma argumentação que salientava a necessidade premente de o estado viabilizar o trabalho católico. $O$ discurso nacionalista e católico insistia na necessidade de revisão dos rumos tomados pela república brasileira. Era necessário despi-la do "artificialismo" de inspiração "exógena", representado pelo liberalismo e agnosticismo, a fim de adequar plenamente as instituições nacionais ao "caráter" do povo brasileiro. D. Sebastião Leme, o futuro articulador da neocristandade brasileira, já em 1916 evidenciava a oposição entre o povo, identificado como o "coração" da pátria, o qual mantinha incólume do sentimento católico, e o estado, indiferente em matéria de fé :

15 Não é depois de quatro séculos de vida nacional que um golpe ousado, em antinomia com todas as leis da evolução histórica, consegue estabelecer um divórcio odiendo entre o coração da pátria e o seu organismo político. ${ }^{13}$

Nota-se a permanência dessa argumentação, na qual o povo brasileiro é representado como a grande maioria católica, cuja fé é necessário o estado salvaguardar, sob pena de perder a legitimidade e patrocinar a desordem. Quinze anos após a Pastoral de D. Leme, o episcopado, por ocasião das comemorações da inauguração da estátua do Cristo Redentor, advertia ao governo provisório :

Banido dos conselhos da Nação, Deus (...) terá sempre guarida no coração do povo, mas o Estado e, portanto, os seus governantes, estará desamparado de todo espírito de ordem, respeito e disciplina : jamais poderá firmar-se na paz duradoura e fecunda, porque sem alicerces no amor e consideração dos governados. ${ }^{14}$

A hierarquia católica insistia nos seus pronunciamentos em qualificar-se como estreitamente vinculada ao povo. Reafirmava junto ao Estado, interlocutor por excelência do seu discurso, sua força junto à sociedade através de gigantescas 
concentrações e celebrações, como os Congressos Eucarísticos, onde sua capacidade de mobilização era reiterada. Todo esse esforço articulava-se com a estratégia de retomada do poderio espiritual católico, integrante do plano de edificação de uma nova cristandade. Funcional a essa estratégia foi a representação da realeza de Cristo, cujo reinado sobre o Brasil era proclamado solenemente nas concentrações e comemorações católicas. Em uma conjuntura de normalidade constitucional como a que aconteceu o 5․ Congresso Eucarístico Nacional de 1948 continuava a hierarquia católica a reconhecer apenas uma ordem social : aquela que respeitasse e que se harmonizasse com o ensinamento da igreja católica. Fora da cooperação interclassista sedimentada pela igreja, só poderia haver o caos. Acima da soberania das maiorias, acima da vontade humana celebrada em contrato político estavam os direitos de Deus, o reinado espiritual de Cristo, conforme palavras do arcebispo de Belém do Pará, D. Mário de Miranda Vilasboas, no $5^{\circ}$. Congresso Eucarístico Nacional, ao dizer que Cristo Rei era o único fundamento da ordem social "que só é ordem se é cristã e só é social se inspirada na justiça" capaz de realizar "a caridade, mistério inefável de unidade na multiplicidade".$^{15}$ A solidariedade orgânica social era vista no discurso de D. Mário de Miranda Vilasboas fundamentada na eucaristia. Portanto, os Congressos Eucarísticos eram representados como a celebração do Reinado de Cristo, capaz de instaurar a paz social e fugir da revolução :

A eucaristia é a ordem social. Os grãos de trigo se juntaram. Triturados e amassados formaram um só pão. Os frutos da vide se uniram. Despedaçados e esmagados formaram um só e mesmo vinho. A ordem, harmônica disposição e conspiração de partes, é unidade, assim como a sociedade é multiplicidade. Não haverá jamais, ordem social enquanto não houver trituramento, pela renúncia e esmagamento, pela imolação, dos membros, para que esplenda a harmonia e união da comunidade. $\mathrm{Na}$ base, pois, de toda lídima reforma social, o sacrifício, a cruz e o altar. A eucaristia, união dos cristãos com Cristo e união comum dos cristãos entre si mesmos, é a garantia da ordem social. Estamos vivendo o século da questão social. Ordem é estabilidade e tranquilidade. Questão é contenda e discussão. Deus permita saibamos bem colocar o estado da questão para chegarmos, quanto antes, à estabilização da ordem, estabilização que nem sempre coincide com a padronização da vida moderna, mas que só se realizará no fundamento dos valores eternos. ${ }^{16}$

Onde a mera racionalidade do discurso teológico acerca da realeza de Cristo sobre o mundo não tinha condições de penetrar ; em um país onde a religiosidade sacramental e a vivência plena dos preceitos católicos longe estavam de ser uma unanimidade, a hierarquia buscava um arsenal de diferentes formas de linguagem, capaz de conviver com o imaginário social. As grandes mobilizações públicas, principalmente os Congressos Eucarísticos, onde o povo era visto como "súdito de Cristo-Rei", a adoção de uma imagem hierática, que se representava como acima da transitoriedade do poder burguês pela hierarquia episcopal ${ }^{17}$, tudo isso reforçava funcionalmente a autoridade de uma instituição que se credenciava frente ao estado como importantíssima interlocutora, ela mesma capaz de matriciar uma elaboração de imagens extremamente mobilizadora e capaz de sedimentar a coesão social.

A ordem e a paz, capazes de neutralizarem a ação "deletéria" daqueles que pensavam a sociedade de forma diferente da solidariedade orgânica eram colocadas como virtudes inerentes ao catolicismo. $O$ alçar-se acima do turbilhão de interesses atomizados era visto como uma característica intrínseca do saber católico. Os sacramentos e a tradição da igreja eram valorizados como instrumentos de coesão social de uma força indestrutível. o papel unitivo do sacramento da eucaristia era, por exemplo, cantado no 
hino do primeiro Congresso Eucarístico Nacional, realizado em 1933 em Salvador ${ }^{18}$. O hino, da autoria de D. Aquino Correa, ao mesmo tempo em que apelava à sacralização da história do Brasil, remetia a eucaristia para a imagem solar. Assim como o sol, o "astro-rei" era uma força incontrolável e necessária, capaz de anunciar a cada aurora a manutenção da vida, a hóstia consagrada, vista como marco fundador de nossa história, era representada como fundamento do verdadeiro viver nacional :

Sobre os mares azuis da Bahia, Foi que outrora raiou, toda em luz, A Hóstia Santa, qual sol que alumia, $\mathrm{O}$ almo berço da Terra da Cruz. ${ }^{19}$

Assim, os Congressos Eucarísticos deveriam apelar para um brilho externo, para uma grandiloquência imagética capaz de explicitar a majestade de Cristo sobre a sociedade e sobre os homens. À frieza de uma elite dirigente laica e indiferente em matéria de religião, deveriam responder os católicos com manifestações públicas, nas quais o povo reconheceria e celebraria o reinado de Cristo. Por isso a preocupação da hierarquia católica em mobilizar a população e tornar visível pelo brilho externo desses Congressos o reinado de Cristo. Por exemplo, D. Antônio Reis, bispo de Santa Maria, RS, escrevia em 1935 que o próximo Congresso Eucarístico que seria celebrado em comemoração aos vinte e cinco anos da diocese deveria ostentar organização e esplendor, dignos de uma celebração pública ao maior dos reis :

Mas é mister também que todos entendamos a grave responsabilidade que nos incumbe de não pouparmos esforços para que o triunfo de Nosso Divino Rei Sacramentado seja o mais completo possível, tanto pelo fervor religioso e transformação interior dos nossos corações como pelo brilho exterior das manifestações públicas que lhe serão prestadas em nossos templos, ruas e praças, por onde as camadas sociais, irmanadas em si pela luz de uma mesma fé, pela chama de um mesmo amor e pela harmonia dum só hino triunfal. ${ }^{20}$

As imagens que remetem aos atributos da realeza de Cristo são reiteradas na mensagem enviada por Pio XII aos católicos de Porto Alegre, por ocasião da celebração do quinto Congresso Eucarístico Nacional que aconteceu em 1948, em Porto Alegre, RS. O ostensório da hóstia era representado como o trono de Jesus Cristo e o povo brasileiro como a "corte" de Cristo Rei :

Pela quinta vez em breve volver de anos, se reúne hoje o católico povo brasileiro em cortes de honra à volta do Rei divino, para prestar-lhe as devidas homenagens da sua fé sincera, da sua esperança firme, do seu amor agradecido. ${ }^{21}$

25 A vinculação entre a realeza de Cristo e a eucaristia era vista pelo papa apelando para a metáfora do corpo. No corpo místico de Cristo a eucaristia ocupava o lugar do coração. Como sem coração não há vida, a eucaristia era representada como o centro da vida da igreja. Como na exegese católica da narrativa evangélica, a última ceia representa a um só tempo a instituição da eucaristia e do sacerdócio ; como sem o sacerdócio católico não pode haver eucaristia, indiretamente celebrava-se nos Congressos Eucarísticos, a própria hierarquia católica :

Quando o Rei divino, prestes a sair deste mundo para o Padre, decidiu no excesso do seu infinito amor ficar conosco até a consumação dos séculos, não foi para se condenar a ser um eterno prisioneiro esquecido nas trevas dos sacrários abandonados! Nem foi só ou principalmente para sair deles de quando em quando a receber, em tronos esplendentes de flores, as homenagens de adoração e glória, que à sua infinita Majestade, quanto mais escondidas, tanto são mais devidas! Se ficou, foi para ser o Coração eternamente vivo e palpitante do seu corpo místico ; para ser o centro 
propulsor, a fonte manancial de vida e vida abundante para a sua igreja e para todos e cada um de seus membros. ${ }^{22}$

Essa tentativa de salientar, através do brilho triunfalista a superioridade da organização eclesial é amplificada na descrição que o padre Dainese fez da presença do Papa ao Congresso Eucarístico Internacional, celebrado em Roma no ano de 1922. Nesta descrição todo um cenário converge para a figura papal, apresentada como uma "visão do céu", própria do Vigário de Cristo Rei na terra :

(...) por fim aparecem os trinta cardeais precedendo imediatamente a sede gestatória, mal esta se avista sob o pálio branco e entre os alvos "flabelli", prorrompem frenéticos aplausos e delirantes aclamações ; o povo entoa o Tu es Petrus e do alto da sacada interior da basílica, as trombetas tocam a marcha triunfal. Pio XI, revestido de amplo manto branco e coroado da tiara, aparece sobre aquele mar de cabeças qual uma visão do céu. ${ }^{23}$

Os pronunciamentos da hierarquia e a leitura da imprensa católica da primeira metade do século XX apontam, assim, para uma tentativa de valorização da instituição eclesial, hábil a afirmar sua funcionalidade, não apenas como óbvia força legitimante e mobilizadora, mas como reserva moral, capaz de emprestar às instituições políticas e à vida nacional uma força unitiva embasada em princípios colocados totalmente fora da vontade dos homens, de suas lutas estreitas e seus contratos mesquinhos.

\section{Concluindo}

Integrando o esforço intelectual de pensar o Brasil, construindo sua identidade coletiva, a hierarquia católica trabalhou tentando dar um sentido à própria história nacional. Sentido esse que aparecia nos seus pronunciamentos e na sua imprensa sem contornos definidos com a história do catolicismo no Brasil. Essa identificação mostrar-se-á funcional no afã de estender a toda a sociedade brasileira os "perigos e inimigos" que ameaçavam a igreja, podendo assim reclamar que o estado igualmente os assumisse.

Os Congressos Eucarísticos mostraram total funcionalidade na difusão dessas representações da nação e do povo. Representaram ocasiões, por excelência, para que se manifestasse esta tentativa de nomear a realidade, de estabelecer o projeto de uma "essência" católica sobre o Brasil na primeira metade do século XX. Ainda o país não aprofundara a vivência de um pluralismo religioso capaz de antepor-se a estas manifestações, ainda as elites políticas viam nas celebrações triunfalistas católicas uma ocasião ímpar de auferir dividendos simbólicos, aproximando-se de uma nebulosa imagética caríssima à boa parte da população brasileira. Por outro lado, ainda a hierarquia católica mantinha o projeto de, através da mediação das elites dirigentes, chegar à recristianização do povo inteiro. Os Congressos Eucarísticos da primeira metade do século XX representaram no Brasil, ocasiões nas quais a celebração maciça do público acatamento a Cristo Rei mobilizava a opinião pública, reforçando e pondo em evidência as reservas simbólicas de uma igreja, cuja força política não podia ser desprezada pelos detentores do poder. 


\section{BIBLIOGRAFIA}

A RESPEITO DO TE DEUM DE 7 DE SETEMBRO. (1922) Mensageiro do Coração de Jesus, N.318, p. 678. BRASIL. A IGREJA E AS FESTAS DO CENTENÁRIO DA INDEPENDÊNCIA.(1922) Mensageiro do Coração de Jesus. N.318, p. 678.

BECKER, D. João (1922). . Discurso pronunciado por D. João Becker depois da missa celebrada na igreja Nossa Senhora das Dores em 7 de setembro de 1922 Unitas, p. 292.

BECKER, D. João (1948). Oração pronunciada na missa inaugural do Primeiro Congresso Eucarístico Nacional, na catedral do Rio de Janeiro, em 27 de setembro de 1922, por D. João Becker, arcebispo metropolitano de Porto Alegre Unitas. N. 09, p. 350-351.

CANETTI, Elias (1983). Massa e poder. São Paulo : Melhoramentos.

CORREA, D. Aquino (1933). Hino do Primeiro Congresso Eucarístico Nacional. Mensageiro do Coração de Jesus. N. 448, p. 561.

EPISCOPADO BRASILEIRO (1922). Carta Pastoral do Episcopado Brasileiro ao clero e fiéis de suas Dioceses por ocasião do Centenário da Independência. Papelaria e Tipografia Marques, Araujo \& Cia., Rio de Janeiro.

GUIMARÃES, Lúcia Paschoal (2002). Francisco Adolpho de Varnhagen In : MOTA,Lourenço Dantas (Org.). Introdução ao Brasil : Um banquete no trópico 2. Editora SENAC, São Paulo.

ISAIA, Artur Cesar (1988). Catolicismo e autoritarismo no Rio Grande do Sul. EDIPUCRS, Porto Alegre.

ISAIA, Artur Cesar (2003). A hierarquia católica brasileira e o passado português. In : Szesz, C.M. et al. (orgs.). Portugal-Brasil no século XX. Sociedade, Cultura e Ideologia. EDISC> Bauru : EDISC.

LAMOUNIER, Bolivar (1978). Formação de um pensamento autoritário na Primeira República. Uma interpretação In: FAUSTO, Bóris. (org.). História Geral da Civilização Brasileira. Difel, São Paulo.

LEME. D. Sebastião (1916). Carta Pastoral. Vozes, Petrópolis.

MENSAGEM DO EPISCOPADO NACIONAL A GETÚLIO VARGAS. Rio de Janeiro, 12 de out., de 1931. Arquivo Getúlio Vargas, CPDOC-FGV-RJ. Ref. GV31.10.12/2.

MICELLI, Sérgio (1988). A elite eclesiástica brasileira. Editora Bertrand Brasil, Rio de Janeiro.

PIO XI (1950). Sobre Cristo Rei - Quas Primas. Vozes, Petrópolis.PIO XII. (1948). Mensagem de S. Santidade Pio XII ao povo brasileiro, transmitida pela Rádio Vaticana no dia 31 de outubro logo depois de encerrada a missa pontifical de encerramento do 5‥ Congresso Eucarístico Nacional de Porto Alegre In: CONGRESSO EUCARÍSTICO NACIONAL. Coletânea. Porto Alegre, Comissão Central Organizadora. REALEZA DE CRISTO SOBRE O BRASIL (1922). Mensageiro do Coração de Jesus. N. 318, p. 688-689.

REIS, D. Antônio (1935). Carta Pastoral In : CONGRESSO EUCARÍSTICO DIOCESANO. A eucaristia e a sociedade. Lembrança do Congresso Eucarístico Diocesano de Santa Maria. s.n.t.

REVISTA DOS INTERESSES DO SAGRADO CORAÇÃO DE JESUS (1922). Mensageiro do Sagrado Coração de Jesus. N. 16,p. 559.

VILASBOAS, D. Mário de Miranda (1948). Sermão In: CONGRESSO EUCARÍSTICO NACIONAL. Coletânea. Comissão Organizadora, Porto Alegre. 


\section{NOTAS}

1. PIO XI, 1950, 04.

2. EPISCOPADO BRASILEIRO, 1922, 04.

3. Sobre Varnhagen e sua concepção historiográfica ver, entre outros : GUIMARÃES, 2002. Sobre o parentesco do discurso católico da primeira metade do século XX com a narrativa histórica de Varnhagen ver : ISAIA, 2003.

4. BECKER, 1948, 10-11.

5. REALEZA DE CRISTO SOBRE O BRASIL, 1922, 688-689.

6. BRASIL. A IGREJA E AS FESTAS DO CENTENÁRIO DA INDEPENDÊNCIA, 1922, 678.

7. A RESPEITO DO TE DEUM DE 7 DE SETEMBRO, 1922, 678.

8. CANETTI, 1983. Elias.

9. BECKER, 1922, 246. D. João.

10. BECKER, 1922, 292.

11. LAMOUNIER, 1978, 357.

12. ISAIA, 1998.

13. LEME, 1916, 94.

14. MENSAGEM DO EPISCOPADO NACIONAL A GETÚLIO VARGAS. Rio de Janeiro, 1931.

15. VILASBOAS, 1948, 63.

16. VILASBOAS, 1948, 63.

17. Ver a este respeito, MICELLI, 1988.

18. O Congresso Eucarístico de 1922, celebrado no Rio de Janeiro, não é considerado o primeiro Congresso Eucarístico Nacional.

19. CORREA, 1933, 561.

20. REIS, 1935, 17.

21. PIO XII, 1948, 17.

22. PIO XII, 1948, 17.

23. REVISTA DOS INTERESSES DO SAGRADO CORAÇÃO DE JESUS, 1922, 559.

\section{RESUMOS}

Este texto explora a fala da hierarquia católica brasileira explicitada nos Congressos Eucarísticos, celebrados na primeira metade do século XX. Os Congressos Eucarísticos são encarados como celebrações que reiteravam um projeto nomeador da realidade brasileira pela hierarquia católica, no qual não haveria possibilidade de pensar-se a realidade e a história nacional fora do catolicismo. Esses Congressos Eucarísticos, embasados na representação de Cristo Rei, ritualizavam o projeto de um Brasil católico, no qual Cristo deveria reinar, acima das elites dirigentes e do estado. Os Congressos Eucarísticos são aqui tratados como eventos mobilizadores de uma constelação de imagens, que apelando para bens simbólicos monopolizados pela igreja, deveriam remeter à obviedade de em Brasil católico e do reinado inquestionável de Cristo.

Ce texte explore le discours de la hiérarchie catholique brésilienne dans les Congrès eucharistiques célébrés dans la première moitié du XXe siècle. Les Congrès eucharistiques sont considérés comme des célébrations qui intégraient un projet de la réalité brésilienne élaboré par la hiérarchie catholique, dans lequel il n'y avait pas la possibilité de penser la réalité et l'histoire 
nationale en dehors du catholicisme. Ces Congrès eucharistiques, basés sur la représentation du Christ-Roi, ritualisaient le projet d'un Brésil catholique, où le Christ devait régner au-dessus des élites dirigeantes et de l'État. Ici les Congrès eucharistiques sont traités comme des événements mobilisateurs d'une constellation d'images qui font appel à des biens symboliques monopolisés par l'Eglise et qui devaient se référer à l'évidence d'un Brésil catholique et dun règne incontesté du Christ.

ÍNDICE

Mots-clés: imaginaire catholique, congrès eucharistiques, représentation du Christ-Roi

Palavras-chave: imaginário católico, congressos Eucarísticos, representação de Cristo Rei

\section{AUTOR}

\section{ARTUR CESAR ISAIA}

Universidade Federal de Santa Catarina, Departamento de História, Programa de Pós-Graduação em História, pesquisador do $\mathrm{CNPq}$ 